\title{
A Licenciatura em Psicologia na Década de 1960: Um estudo do Caso do
}

\author{
Curso da UFMG \\ Deolinda Armani Turci* \\ Universidade do Estado de Minas Gerais - UEMG, Belo Horizonte, MG, Brasil \\ ORCID: http://orcid.org/0000-0003-1820-2092 \\ Sérgio Dias Cirino** \\ Universidade Federal de Minas Gerais - UFMG, Belo Horizonte, MG, Brasil \\ ORCID: https://orcid.org/0000-0002-5835-0068 \\ Érika Lourenço**** \\ Universidade Federal de Minas Gerais - UFMG, Belo Horizonte, MG, Brasil \\ ORCID: https://orcid.org/0000-0002-2681-3021
}

\section{RESUMO}

No intuito de compreendermos o lugar da licenciatura na formação de psicólogos, logo após a Lei $n^{\circ} 4119 / 62$, este artigo apresenta um estudo de caso sobre a inserção da licenciatura no curso de Psicologia da Universidade Federal de Minas Gerais (UFMG) durante a década de 1960 e suas contribuições para os ex-alunos, ingressantes nesse período. O estudo historiográfico é fruto de pesquisa de doutorado e utiliza como procedimento metodológico a análise de fontes primárias e entrevistas com ex-alunos. Os resultados demonstraram que a licenciatura em Psicologia foi inserida no curso da UFMG desde a primeira turma de entrada de alunos de 1963 e ofertada no formato de cumprimento obrigatório para todos os alunos daquele ano. Em 1965, a licenciatura tornou-se uma formação opcional e, a partir de então, cada vez menos alunos passaram a optar por ela. Os entrevistados confirmaram os dados obtidos na análise documental relativos ao funcionamento da modalidade e apontaram os aspectos metodológicos aprendidos durante a licenciatura como as principais contribuições para suas formações profissionais. Esperamos que a pesquisa contribua com as reflexões sobre a oferta da licenciatura na formação dos psicólogos brasileiros e com os estudos históricos sobre a Psicologia no Brasil.

Palavras-chave: licenciatura em Psicologia, UFMG, história da Psicologia, década de 1960.

\section{The Teaching License Degree in Psychology in the 1960s: A Case Study of}

\author{
the UFMG Course
}

\author{
ABSTRACT \\ In the intent to understand the place of the Teaching License Degree in the training of \\ psychologists, right after the Law $\mathrm{n}^{\circ} 4119 / 62$, this article presents the case study on the


insertion of the Teaching License Degree in Psychology course of the Federal University of Minas Gerais (UFMG) during the decade of 1960 and its contributions to the former students, who entered this period. The historiographic study is the result of doctoral research and uses as methodological procedure the analysis of primary sources and interviews with former students. The results showed that the Teaching License Degree in Psychology was inserted in the course of UFMG since the first class of students entrance in 1963 and offered in the form of compulsory compliance for all the students of that year. From 1965, as the Teaching License Degree became an optional training, fewer and fewer students opted for it. The interviews confirmed the data obtained in the documentary analysis related to the operation of the modality and pointed out the methodological aspects learned during the Teaching License Degree as main contributions to the professional formation of the same. We hope that the research contributes with the reflections on the offer of the Teaching License Degree in the training of Brazilian psychologists and with the historical studies on Psychology in Brazil.

Keywords: teaching license degree, UFMG, history of psychology, decade of 1960.

\section{La Licenciatura en Psicología en la Década de 1960: Un Estudio del Caso}

\section{del Curso de la UFMG}

\section{RESUMEN}

En este artículo se presenta el estudio de caso sobre la inserción de la licenciatura en el curso de Psicología de la Universidad Federal de Minas Gerais (UFMG) durante la década de 1960, con el fin de comprender el lugar de la licenciatura en la formación de psicólogos, poco después de la Ley no 4119/62, 1960 y sus contribuciones a los ex alumnos, ingresantes en ese período. El estudio historiográfico es fruto de investigación de doctorado y utiliza como procedimiento metodológico el análisis de fuentes primarias y entrevistas a los ex alumnos. Los resultados demostraron que la licenciatura en Psicología fue insertada en el curso de la UFMG desde la primera clase de ingreso de alumnos en 1963 y ofrecida en el formato de cumplimiento obligatorio para todos los alumnos de ese año. A partir de 1965, como la licenciatura pasó a ser una formación opcional, cada vez menos alumnos optaron por la misma. Los entrevistados confirmaron los datos obtenidos en el análisis documental relativos al funcionamiento de la modalidad y señalaron los aspectos metodológicos aprendidos durante la licenciatura como principales contribuciones para la formación profesional de los mismos. Esperamos que la investigación contribuya con las reflexiones sobre la oferta de la licenciatura en la formación de los psicólogos brasileños y con los estudios históricos sobre la Psicología en Brasil.

Palabras clave: licenciatura en psicología, UFMG, historia de la psicología, década de 1960.

$\mathrm{Na}$ atualidade, as licenciaturas no Brasil formam professores para os anos finais da educação básica. Desde a Lei no 4119, de 1962, que regulamentou a profissão de psicólogos no Brasil, essa modalidade de formação é ofertada nos cursos de Psicologia no país. Naquela 
época, o licenciado que tivesse sido aprovado nas disciplinas de cunho pedagógico nas Faculdades de Filosofia brasileiras poderia atuar no ensino secundário ${ }^{1}$, nomenclatura diferente da atual, mas correspondente ao mesmo segmento educacional.

Desde o início do século XXI, nas discussões e definições sobre as Diretrizes Curriculares Nacionais (DCNs) ${ }^{2}$ para os cursos de Psicologia no país, a oferta da licenciatura na formação do psicólogo tem sido fruto de constantes debates entre os profissionais dessa área. Tal oferta vem sendo fragilizada ou até mesmo extinta, apesar da Lei no 4119/62 ainda estar em vigor. É significativo dizer que, das três modalidades derivadas dessa legislação, a licenciatura é a única que sofre esse tipo de questionamento.

Sabemos que, de certa forma, as incertezas sobre a oferta da licenciatura são pertinentes, principalmente se levarmos em consideração o campo de atuação do profissional formado nessa modalidade. No Brasil, poucas instituições contratam psicólogos licenciados para lecionar em seus cursos, uma vez que não há disciplinas de Psicologia obrigatórias segundo a legislação para o ensino médio no país e que estas, quando fazem parte dos currículos de cursos técnicos ou profissionalizantes, em geral são ministradas por profissionais não licenciados, como ressaltam Fontoura e Silva (2013).

Outro ponto importante é que, tanto na pesquisa do Conselho Federal de Psicologia (CFP), publicada em 1988, quanto nos textos de Bastos (1988), Bastos e Gomide (2010) e Bastos, Gondim e Borges-Andrade (2010) sobre o trabalho dos psicólogos brasileiros, as evidências são de que a área clínica ainda é a preferida e predominante entre os profissionais formados no Brasil. Mesmo diante de novos espaços de atuação na contemporaneidade, como os de demanda social, evidenciados pelo estudo de Bastos et al. (2010), as áreas de concentração da atuação dos profissionais ainda são, nessa ordem, a área clínica, de saúde (área que não aparecia na primeira pesquisa), organizacional, escolar e, por último, da docência.

Na pesquisa de 1988, o índice de atuação dos psicólogos na licenciatura mostrou-se bastante reduzido, menos de 5\% dos pesquisados. Já na pesquisa de 2010, a licenciatura não aparece como atividade dos psicólogos docentes que, quase em sua totalidade (98,3\%), estão voltados para o ensino superior e exercem, concomitantemente, funções como elaboração de pareceres, laudos e psicodiagnósticos, supervisão de estágios acadêmicos, aplicação de testes psicológicos, planejamento de políticas educacionais e participação em equipes técnicas e cargos administrativos (Gondim, Bastos \& Peixoto, 2010). Bastos, Gondim e Borges-Andrade (2010) apontam ainda que o aumento da docência como atividade profissional do psicólogo deve-se à expansão dos cursos de Psicologia e do ensino superior no país. 
Além da desvalorização da licenciatura como campo de atuação dos psicólogos, a pesquisa de Izidoro, Jorcuvich e Costa (2015) retrata que pouquíssimos cursos de Psicologia oferecem a modalidade no país e que há, nestes, uma significativa discrepância entre a carga horária da licenciatura e a carga horária do bacharelado, sendo que em alguns cursos as disciplinas feitas no bacharelado são aproveitadas para a formação na licenciatura.

Mediante todas essas evidências, nossas inquietações voltaram-se para os anos que sucederam a Lei $\mathrm{n}^{\circ}$ 4119/62. Começamos a nos questionar sobre como a licenciatura havia sido inserida nos cursos de Psicologia após a exigência legal e se o panorama sobre ela era o mesmo que o atual. Decidimos, então, estudar o caso do curso de Psicologia da UFMG, e traçamos como objetivo da pesquisa compreender como a licenciatura foi inserida nesse curso e quais seriam as contribuições da modalidade para seus egressos, ex-alunos da década de 1960.

\section{Método}

Tendo como referências os trabalhos produzidos no campo da História da Psicologia, este estudo, de cunho historiográfico, utiliza como metodologia de pesquisa a análise de documentos disponíveis no Setor de Arquivo Acadêmico da Graduação da atual Faculdade de Filosofia e Ciências Humanas (FaFiCH) da UFMG e de entrevistas com egressos do curso de Psicologia da mesma universidade, ingressantes durante a década de 1960. Nos arquivos pesquisados consultamos as pastas dos alunos, que continham formulários de matrícula, cópias de documentos, atestados médicos, de saúde e de imunização, resultado de abreugrafia, cartas de recomendação, atestados de bons antecedentes e nada consta emitidos por órgão da Polícia Civil, procurações, solicitações de abono de faltas e outras direcionadas à direção da faculdade, histórico escolar, certificados de estágios curriculares e extracurriculares, fichas de controle de estágio, solicitação de diplomas, entre outros documentos. Foram examinados nos arquivos, também, ementas e programas das disciplinas, diários de classe, livros de atas, documentos administrativos diversos, entre outros referentes ao período temporal da pesquisa.

Ainda no mesmo setor, localizamos uma listagem com os nomes dos alunos que iniciaram o curso de Psicologia na UFMG durante a década de 1960 e, através de consultas diversas na Internet, pelo Google e Facebook, conseguimos localizar e entrevistar 11 desses ex-alunos. As entrevistas semiestruturadas ocorreram entre os meses de janeiro e maio de 2018, em datas e horários pré-agendados, em local de escolha dos entrevistados e gravadas com o consentimento deles, que também assinaram o Termo de Consentimento Livre e 
Esclarecido (TCLE). As gravações foram transcritas e encaminhadas para os entrevistados, por e-mail, para revisão, sendo que apenas dois deles nos devolveram as transcrições com pequenos ajustes e alterações gramaticais.

\section{Resultados}

A partir da análise documental, identificamos que o curso de Psicologia da UFMG foi criado no ano de 1962 na então Faculdade de Filosofia, Ciências e Letras (FFCL), com entrada anual e primeira turma começando no início do ano de 1963.

Importante dizer que o processo de instalação do curso teve início muito antes de seu funcionamento e que refletia as demandas e necessidades sociopolíticas locais, contando, inclusive, com a participação de vários profissionais que já atuavam com as práticas psicológicas no estado - como Helena Antipoff (25 de março de 1892- 09 de agosto de 1974) e Pedro Parafita de Bessa (06 de março de 1923-17 de setembro de 2002), professores da disciplina de Psicologia Educacional na mesma faculdade desde a década de 1940 e envolvidos com as discussões sobre a profissão e sua regulamentação no país.

Foi possível perceber, nas atas do Conselho Técnico Administrativo (CTA) da FFCL, que as discussões para a abertura do curso intensificaram-se já nos anos de 1960 e 1961, mas que este Conselho achou por bem aguardar a promulgação da legislação que regulamentava a formação e a profissão no país para implementar sua criação.

A licenciatura em Psicologia fez parte do curso desde a primeira estrutura curricular e, para a primeira turma de entrada de alunos, foi ofertada como formação obrigatória, como as demais modalidades, sendo composta pelas disciplinas: Didática Geral, Didática Especial e Administração Escolar. Os alunos foram dispensados de cumprir os créditos da disciplina de Psicologia Educacional, outra cadeira exigida pela legislação da época para todas as licenciaturas brasileiras. A prática de ensino, um estágio também obrigatório à época, na primeira turma foi substituído por um trabalho prático.

Localizamos o diário de classe e a ementa com o programa da disciplina de Didática Geral de 1966, ofertada no $3^{\circ}$ ano do curso, por dois semestres consecutivos - Didática Geral I e Didática Geral II -, com conteúdos que preparavam o aluno para questões mais amplas da docência e para qualquer segmento educacional. Tais conteúdos incluíam desde o conceito de didática, objetivos e campos, níveis do magistério, "deontologia professoral", métodos científico e didático, tipos de métodos didáticos, etapas da aula e procedimentos didáticos, até 
a definição do processo educativo, a aprendizagem, a motivação, diferenças individuais de aprendizagem, tipos de provas, critérios de promoção e reprovação, entre outros.

A disciplina de Didática Especial foi ofertada para a primeira turma durante todo o $4^{\circ}$ ano do curso e, apesar de não termos localizado seu programa, foi possível compreender, a partir da leitura das ementas de outras disciplinas similares, para outros cursos da FFCL, que a matéria era voltada para questões de ensino e aprendizagem de conteúdos de Psicologia. Seguindo certo propósito, a Didática Especial era ofertada após o aluno ter concluído a disciplina de Didática Geral. Dessa forma, o estudante teria conhecimento sobre os aspectos mais gerais da didática para, sequencialmente, compreender as especificidades da didática aplicada a seu curso de origem.

Quanto à disciplina de Administração Escolar, esta foi ofertada para a mesma turma também no $4^{\circ}$ ano do curso. Após localizarmos dois programas da disciplina (ainda que sem data de oferta), identificamos que seus conteúdos eram voltados para noções gerais e conceituais sobre administração, tanto pública quanto privada, cargos e operações administrativas, organização e importância do Ministério da Educação e Cultura, administração escolar, seus sistemas e organização, principais artigos da Lei de Diretrizes e Bases da Educação Nacional, estatuto do funcionalismo público, deveres e direitos dos profissionais da escola, entre outros assuntos. Apesar do vasto conteúdo, não identificamos nenhum tópico específico ao segmento do ensino secundário.

De acordo com o "Currículo Pleno do Curso de Psicologia", uma nova estrutura curricular foi estabelecida para a segunda turma de entrada no curso em 1964. Tanto as disciplinas do bacharelado quanto da "Formação de Psicólogo" foram ampliadas de 30 para 35 obrigatórias, sendo que das disciplinas anteriormente vinculadas à licenciatura, somente a de Didática Geral, lecionada no $3^{\circ}$ ano do curso, permaneceu como obrigatória, passando a pertencer ao quadro de disciplinas do bacharelado.

As outras disciplinas da licenciatura que eram lecionadas no $4^{\circ}$ ano tornaram-se de caráter opcional. Para concluí-las, os alunos deveriam se dirigir para a Faculdade de Educação (FAE) ${ }^{3}$ da mesma universidade. Além da Didática Geral, as demais disciplinas que compuseram a licenciatura para essa turma foram: Administração Escolar, Didática Especial, que passou a ser denominada "Didática Especial em Psicologia Educacional”, e estágio, que nesse currículo era denominado "Estágio em Psicologia Educacional”.

Localizamos dois programas da disciplina de Didática Especial em Psicologia Educacional, um de 1967 e outro de 1970, com conteúdos muito semelhantes e totalmente direcionados à formação do professor de Psicologia Educacional para atuação no curso 
colegial Normal. O programa de 1967 apresenta ainda um tópico relativo à formação do orientador educacional, e em sua bibliografia encontramos uma significativa quantidade de referências relacionadas a medidas e testes em educação.

Para a entrada de alunos em 1965, a disciplina de Didática Geral foi retirada da estrutura curricular do bacharelado e inserida novamente na licenciatura. Para fazer as disciplinas da licenciatura, todas optativas, os alunos deveriam cursá-las na FAE. ${ }^{4}$

O currículo geral do curso de Psicologia de 1966 teve um aumento significativo no número de disciplinas para o bacharelado e para a "Formação do Psicólogo". Além disso, os alunos tinham de cumprir 500 horas de estágio. Assim, cada vez mais, os alunos passaram a preterir a licenciatura, que era um curso opcional. Identificamos também que, de maneira diferente dos procedimentos utilizados nos demais cursos da FFCL, as disciplinas da licenciatura cursadas pelos alunos de Psicologia não constavam em suas fichas individuais nem no "Currículo Pleno" do curso. Era como se essa formação não existisse ou que estivesse implícito no Currículo Pleno a oferta da modalidade.

Após 1967, a carga horária total do curso de Psicologia da UFMG foi anualmente ampliada e o curso passou a ser ofertado em período integral. Em 1969, por exemplo, a carga horária total passou para 3735 h/a, mais 500 horas de estágio. As disciplinas da licenciatura permaneceram as mesmas legisladas pelo Parecer do Conselho Federal de Educação (CFE) $n^{\circ}$ 292/62 - Didática Geral, Administração Escolar, Didática Especial e Prática de Ensino - até 1969. A partir de então, por meio da Resolução n 12/69, a Coordenação de Ensino e Pesquisa da UFMG fixou a carga horária e os conteúdos para a formação pedagógica nas licenciaturas da instituição, que ficavam a cargo da FAE, para 360 horas de aula e 45 horas para as práticas de ensino, sendo as disciplinas que a compunham: Didática (120 h/a), Estrutura e Funcionamento do Ensino de $2^{\circ}$ Grau (60 h/a), Prática de Ensino (sob a forma de estágio supervisionado de 45 h/a), Introdução à Educação (60 h/a) e Psicologia da Educação (foco na adolescência e aprendizagem, com 120 h/a, que os alunos do curso de Psicologia eram dispensados), totalizando $405 \mathrm{~h} / \mathrm{a}$ para a licenciatura.

Identificamos, em um formulário de matrícula de 1970, a informação de que, terminada a terceira série do curso de Psicologia, o aluno deveria optar entre o curso de licenciatura e o de bacharelado, sendo o último comum ao curso de "Formação de Psicólogo" e a carga horária da licenciatura, de 600 h/a, no mínimo. Supomos que essa informação como um todo pudesse desestimular o aluno a fazer a licenciatura, além do que a carga hora apresentada para a licenciatura era divergente do exposto pela Resolução $n^{\circ}$ 12/69 da Coordenação de Ensino e Pesquisa da UFMG. 
Além disso, os alunos que entraram no curso a partir de 1969 contaram, daí em diante, com outro empecilho para fazer a licenciatura: em 1972 a Faculdade de Educação começou a funcionar em um campus diferente de onde operava o bacharelado e a "Formação de Psicólogos”, numa distância de aproximadamente $10 \mathrm{~km}$. Para Souza (2016), esse fato trouxe também um problema de ordem prática na própria organização dos cursos da UFMG, inclusive pela falta de integração entre as unidades quanto à oferta das disciplinas de formação de professores.

Sem nos esquecermos das palavras de Antunes (2008) de que a memória é seletiva, multideterminada, localizada em um espaço e tempo específicos e que vamos pincelando-a a partir de nossos olhos do presente, as entrevistas com os ingressantes da década de 1960 contribuíram para uma visão mais ampliada dos documentos localizados nos arquivos. A partir delas foi possível perceber que as lembranças sobre a licenciatura eram poucas, principalmente quando comparadas a recordações entusiasmadas de professores, metodologias e conteúdos das demais modalidades da formação.

Sobre a licenciatura, os entrevistados da primeira turma relataram que as disciplinas compunham a grade total do curso para a formação de psicólogos, e que, sendo assim, era obrigatório cumpri-las. Eles disseram que nunca questionaram essa obrigatoriedade, já que não tinham muita informação nem sobre a formação em geral nem sobre os detalhes da Lei $n^{\circ}$ 4119/62 - só sabiam que, ao final do curso, sairiam diplomados como psicólogos.

Dos conteúdos e dinâmicas das aulas da licenciatura, a maioria dos entrevistados recordou-se apenas das disciplinas de Didática e do estágio que eram obrigados a cumprir. As demais não foram citadas e, quando mencionadas pela entrevistadora, a maioria dos ex-alunos não recordava de as ter cursado.

Os egressos relataram que a maior parte das disciplinas da modalidade era feita com outros alunos dos demais cursos da Faculdade de Filosofia, e que se aprendia com a diversidade de informações. Para uma das entrevistadas, a convivência com colegas diferentes proporcionou conhecimento e ricas experiências. Segundo ela, após o estágio nas escolas, que eram escolhidas pelos próprios alunos, os estudantes apresentavam relatórios e discutiam as vivências da prática, que em muitas situações eram motivos de risos e muita descontração.

Perguntados se tinham conhecimento sobre o segmento educacional para o qual estariam autorizados a lecionar concluindo a licenciatura, apenas uma das entrevistadas (que inclusive fez a licenciatura, já na década de 1970) soube dizer que era o ensino secundário. Outros entrevistados afirmaram que essa informação não era fornecida pela instituição e que os alunos só sabiam que se cursava a licenciatura para ser professor de Psicologia. 
À medida que as disciplinas da licenciatura passaram a ser opcionais, muitos estudantes decidiram não fazer a modalidade. Segundo uma das entrevistadas, o motivo era a falta de interesse em lecionar especificamente para o ensino secundário. Esse relato, especificamente, nos leva a crer que, ao longo dos anos de funcionamento do curso, os alunos passaram a ter mais informação e a fazer uma opção mais consciente em relação à licenciatura.

Para os entrevistados que optaram por fazer a licenciatura, os motivos que os levaram a tal decisão estavam relacionados à posse do título e de mais uma possibilidade de atuação ou à compreensão de que o título era necessário para a docência no ensino superior, caso de vários relatos. Uma das entrevistadas declarou que, depois de concluir o curso de Psicologia, em 1970, permaneceu na faculdade para fazer a licenciatura. Sua justificativa era de que desejava lecionar no ensino superior e que, para tanto, no caso de cursos que possuíam a licenciatura, o título era necessário e solicitado, recordando, inclusive, que de sua turma, apenas ela se interessou pela licenciatura.

Independentemente da turma ou do ano em que os egressos frequentaram a licenciatura, os entrevistados foram unânimes em relatar que a formação colaborou para suas vidas profissionais. Tal colaboração, entretanto, parece ter se limitado ao aprendizado de aspectos e procedimentos metodológicos, conforme apontam as respostas. Um fato curioso foi que 8 dos 11 entrevistados eram também ex-alunos de Escolas Normais e, para estes, a licenciatura não tinha novidades, apenas reforçava os conteúdos já aprendidos na formação anterior.

\section{Discussão}

A partir da análise das grades curriculares e dos documentos localizados sobre o funcionamento do curso de Psicologia da UFMG, bem como das entrevistas dos alunos ingressantes durante a década de 1960, é possível compreender que a licenciatura nesse curso, pelo menos para as primeiras turmas, não foi ofertada conforme a legislação educacional vigente para a modalidade no país.

O Decreto-lei no 9092/46 do Ministério da Educação e Saúde, ao equiparar os cursos de licenciatura aos de bacharelado, dispôs que, no quarto ano dos cursos das Faculdades de Filosofia, os alunos poderiam optar pela licenciatura. Assim, a oferta de disciplinas da modalidade em cumprimento obrigatório para a primeira turma do curso de Psicologia não condizia com a legislação específica do período, sendo que nos demais cursos da mesma 
faculdade a licenciatura era ofertada como modalidade optativa desde o início de funcionamento deles.

Para a segunda turma de entrada de alunos, já em 1964, os equívocos em relação à licenciatura em Psicologia permaneceram, uma vez que uma das disciplinas da licenciatura foi mantida como obrigatória na grade da modalidade bacharelado, enquanto as demais passaram a ser optativas, ofertadas pelo Departamento de Pedagogia e Didática da Faculdade de Filosofia da universidade.

A pesquisa documental nos mostrou que as disciplinas da licenciatura para os alunos do curso de Psicologia, a partir da turma de 1965, não eram registradas nem no currículo geral nem na grade do curso de Psicologia, muito menos no histórico escolar dos discentes, o que diferia da prática dos outros cursos da mesma faculdade. Para nós, se o aluno fez as disciplinas, mesmo que ofertadas por outros departamentos, os registros deveriam constar como parte de seu histórico curricular e também da grade curricular do curso, já que a modalidade era parte do mesmo.

Não identificamos o que levou à ausência dessas informações. Supomos que, de forma geral, e segundo Lemos (2008), os cursos de Psicologia não tinham como foco o aluno que desejava ser docente. Além disso, o próprio significado de ser docente no ensino secundário na década de 1960 não era muito significativo. Candau (1987) recorda que a docência nesse segmento educacional era disputada por profissionais liberais de vários segmentos como advogados, autodidatas, engenheiros ou mesmo médicos que se dispusessem a lecionar, e que, de forma geral, os licenciados eram preteridos na disputa com esses profissionais.

Os entrevistados da primeira turma do curso também recordaram que desconheciam os propósitos e o segmento de atuação dos licenciados. Esses dados, somados às informações institucionais desencontradas sobre a licenciatura em Psicologia nos documentos localizados, podem demonstrar desinteresse pela modalidade, inclusive do próprio departamento de Psicologia da UFMG.

Através de suas lembranças, os egressos do curso nos revelaram que a licenciatura não tinha a mesma importância que as demais modalidades de formação. Acreditamos que uma maior valorização do bacharelado e da "Formação de Psicólogos", tanto pelos alunos quanto pela própria instituição, reforçava as ideias de Bernardes (2004) de que a formação voltava-se para os "estudantes de Psicologia que sonham com seus consultórios" (p. 93), mesmo que fossem dentro de escolas, em clínicas particulares ou indústrias.

Para completar, havia o Parecer da CFE n 292/62, que estabelecia que a carga horária da licenciatura deveria ser 1/8 do tempo dos cursos de bacharelado, propondo disciplinas para 
a licenciatura que, conforme Souza (2016), centravam "na perspectiva de pensar o 'que ensinar', a 'quem ensinar', 'como ensinar' e 'em que contexto ensinar'” (p. 201). Assim, se levarmos em consideração a legislação e o fato de os ex-alunos desconhecerem o segmento de atuação da formação, podemos dizer que a licenciatura em Psicologia na UFMG não atendia totalmente aos pré-requisitos legais exigidos, principalmente os relacionados a quem e em que contexto ensinar.

Para completar, segundo os entrevistados, a modalidade contribuiu apenas em relação ao aprendizado ou ao aperfeiçoamento de procedimentos metodológicos, que inclusive foram aplicados em outros segmentos educacionais ou mesmo em outros espaços de atuação - como citado por uma entrevistada que lembrou que a aplicabilidade dos aspectos metodológicos aprendida na licenciatura havia lhe ajudado demais na área clínica.

Não obstante, relembramos que o professor Pedro Parafita de Bessa, um dos idealizadores e professor do curso de Psicologia da UFMG, diretor da FFCL de 1967 a 1969, ano em que foi aposentado compulsoriamente pelo Ato Institucional $\mathrm{n}^{\circ} 5$, foi bastante atuante em comissões do MEC que trataram da regulamentação da formação e da profissão, fato que parece não ter contribuído para que a licenciatura fosse ofertada nessa faculdade dentro das condições exigidas tanto pela Lei $n^{\circ}$ 4119/62 quanto pelas legislações educacionais da época.

Um fato a ser levado em consideração é que a maioria dos entrevistados iniciou a docência no ensino superior tão logo concluiu o bacharelado. Isso porque, de acordo com a Lei $n^{\text {o }} 4119 / 62$, à medida que os novos graduandos fossem formados no país, deveriam substituir os professores dos cursos de Psicologia que não tinham a formação em nível superior. Sendo assim, e, como em muitos casos, já estavam lecionando no ensino superior, esses "alunos-docentes", definitivamente, não tinham a docência no ensino médio como parte de seus planos.

\section{Considerações finais}

A partir da análise dos documentos localizados foi possível compreender que a licenciatura fez parte do curso de Psicologia da UFMG desde a primeira turma de entrada, em 1963, cumprindo a determinação da Lei n 4119/62 e da legislação educacional do período, que previa a oferta da modalidade para todos os cursos instalados nas Faculdades de Filosofia do país. Percebemos, porém, que havia divergência entre o dispositivo legal e o formato de oferta das disciplinas no curso, já que os alunos da primeira turma eram obrigados a cumprir os créditos de todas as disciplinas do currículo. 
Mesmo que a licenciatura, em 1964, tenha passado a ser uma formação opcional, observamos ainda certa confusão na disposição da grade curricular do curso, que manteve uma disciplina da licenciatura como obrigatória e, ainda por cima, vinculada ao bacharelado, enquanto as demais tornaram-se optativas.

Percebemos que, a partir da ampliação da carga horária das disciplinas do bacharelado e da formação de psicólogos, nos anos posteriores a 1965, cada vez mais a licenciatura foi sendo preterida pelos alunos do curso. Do nosso ponto de vista, os dados contribuem para a compreensão de que, na década de 1960, no curso da UFMG, a licenciatura não era incluída como parte da idealização profissional dos alunos, ainda que futuros profissionais. A rejeição à licenciatura pode significar também certo descrédito em relação a essa formação, em detrimento às demais, que eram voltadas para a atuação clínica. Relembramos as palavras de Passos, Goulart, Braga, Abreu e Vasconcelos (2009) de que a ênfase da formação em Psicologia na UFMG era

[...] fortemente voltada para a clínica psicoterapêutica de pacientes diagnosticados como neuróticos... e passada a fase de hegemonia do behaviorismo no curso, caminhou claramente para um privilégio da clínica psicoterapêutica, de tipo individual, caráter curativo e pouco voltada para as práticas comunitárias. (Passos et al., 2009, pp. 162).

Há de se considerar que o interesse por uma formação mais direcionada para a prática de atuação clínica, independentemente do campo de atuação do psicólogo, não era privilégio somente do curso de Psicologia da UFMG. Bernardes (2004) ressalta que "as influências da ditadura, associadas a uma concepção positivista de ciência, e à cultura psi, já arraigada no cotidiano, têm como consequência um tipo de Psicologia privatista, gravitando em torno do indivíduo" (p. 109). Então, é afirmativo que o curso de Psicologia da UFMG reproduzisse esse formato e que não fosse direcionado a formar professores licenciados para a atuação no ensino secundário.

A própria ausência de memórias dos entrevistados sobre a modalidade configura indícios de que os conteúdos vinculados à licenciatura não tinham o mesmo significado que as disciplinas das demais modalidades, bacharelado e "Formação de Psicólogos", que os mesmos lembraram com apreço e consideração sentimental, além dos relatos sobre a ausência de significado da licenciatura para a maioria deles e das referências a conteúdos metodológicos como principal contribuição da formação - conteúdos estes que poderiam ser 
aprendidos em outros segmentos ou em outras matérias do próprio bacharelado. Concluímos que a licenciatura no curso de Psicologia da UFMG nos anos de 1960 foi acompanhada de descrédito tanto por parte da própria instituição quanto por parte dos alunos.

Os dados coletados para esta pesquisa nos levam a crer que dificilmente a licenciatura permaneceria como modalidade de formação nos cursos de Psicologia brasileiros se tivesse sido ofertada em outras instituições, como, por exemplo, em faculdades de Medicina, como foi cogitado à época. Como o objetivo da licenciatura era formar professores de Psicologia para atuarem no ensino secundário, mediante as questões apontadas pela pesquisa podemos afirmar que a modalidade não cumpriu seu papel.

É possível dizer que tanto as dúvidas dos entrevistados sobre a atuação do licenciado à época quanto os equívocos sobre a oferta da modalidade no curso de Psicologia da UFMG não se diferiam muito das confusas informações sobre as funções docentes na própria Lei $n^{\circ}$ 4119/62. No artigo 11 dessa legislação fica claro que era dado ao bacharel, e não ao licenciado, o direito de ensinar Psicologia nos cursos de grau médio, diferindo da legislação educacional em vigor no período. Decerto que a licenciatura no Brasil, independente do curso que estivesse inserida, era uma formação dentro do bacharelado, mas como não era obrigatória, nem todos os bacharéis optavam por ela.

Relembramos ainda que a profissão do psicólogo era requisitada por sua aplicabilidade na resolução de demandas ligadas aos campos da educação, na orientação educacional e profissional, no trabalho em funções como seleção, orientação e treinamento e na clínica,

[...] fortemente associada à Medicina, em uma perspectiva organicista, se transformando em objeto de fetiche para os (as) psicólogos (as) (embora ainda o seja). $\mathrm{O}$ exercício da Psicologia teve, à época, seus limites claramente estabelecidos. O psicólogo sempre foi percebido como auxiliar do médico, podendo, no máximo, exercer funções de orientação e acompanhamento clínico. (Bernardes, 2004, pp. 90).

Nesse quesito, com suas técnicas "privativas", o psicólogo atendia muito mais às demandas de desenvolvimento do Brasil. Formar professores licenciados sem prestígio, como pontuado por Candau (1987), não fazia parte dos planos dos profissionais que já atuavam com a Psicologia no país.

Enfim, a análise histórica que apresentamos, associada às pesquisas de Godim, Bastos e Peixoto (2010) e às demais apontadas acima, nos leva à compreensão de que, de forma geral, desde a Lei $n^{\circ}$ 4119/62, o interesse pela licenciatura em Psicologia era muito pequeno. 
Isso nos leva a refletir se a licenciatura, entendida como uma formação de docentes para o ensino secundário, é realmente indispensável nos cursos de Psicologia brasileiros, inclusive nos dias de hoje, postas as evidências no começo deste texto.

Novas pesquisas podem agregar mais reflexões sobre o tema, inclusive porque concordamos com Izidoro, Jorcuvich e Costa (2015) quando ressaltam a baixa produção bibliográfica sobre a licenciatura em Psicologia no país. Mais estudos podem ajudar a compreender por que, mesmo depois de mais de 50 anos da regulamentação da formação e da profissão, e mediante os impasses e contradições, a licenciatura ainda é ofertada nos cursos de Psicologia no Brasil.

\section{Referências}

Antunes, M. A. M. (2008). Algumas reflexões acerca de minha formação como pesquisadora em história da Psicologia. In R. H. F. Campos (Org.), História da Psicologia: Pesquisa, formação, ensino (pp. 84-93). Rio de Janeiro: Centro Edelstein de Pesquisas Sociais. doi: $10.7476 / 9788599662830$

Bastos, A. V. B. (1988). Áreas de atuação: Em questão o nosso modelo de profissional. In Conselho Federal de Psicologia (Org.), Quem é o psicólogo brasileiro? (pp. 163-193). São Paulo: Edicon. Recuperado de http://newpsi.bvspsi.org.br/ebooks2010/en/Acervo_files/QuemPsicologoBrasileiro.pdf

Bastos, A. V. B., Gondim, S. M. G., \& Borges-Andrade, J. E. (2010). O psicólogo brasileiro: Sua atuação e formação profissional. O que mudou nas últimas décadas? In O. H. Yamamoto \& A. L. F. Costa (Orgs.), Escritos sobre a profissão de psicólogo no Brasil (pp. 257-271). Natal: EDUFRN.

Bastos, A. V. B., \& Gomide, P. I. C. (2010). O psicólogo brasileiro: Sua atuação e formação profissional. In Yamamoto, O. H., Costa, A. L. F. (Orgs). Escritos sobre a profissão de psicólogo no Brasil (pp. 227-255). Natal: EDUFRN.

Bastos, A. V. B., \& Gondim, S. M. G. (Orgs). (2010). O trabalho do psicólogo no Brasil. Porto Alegre: Artmed.

Bernardes, J. S. (2004). O debate atual sobre a formação em Psicologia no Brasil: Permanências, rupturas e cooptações nas políticas educacionais (Tese de doutorado). Programa de Estudos Pós-Graduados em Psicologia Social, Pontifícia Universidade Católica de São Paulo, São Paulo, SP, Brasil. 
Brasil (1962). Lei n. 4.119, de 27 de agosto de 1962. Dispõe sobre os cursos de formação em Psicologia e regulamenta a profissão de psicólogo. Brasília, DF: Presidência da República. Recuperado de http://www2.camara.leg.br/legin/fed/lei/1960-1969/lei4119-27-agosto-1962-353841-normaatualizada-pl.html

Brasil (1962). Parecer CFE n. 292 de 14 de novembro de 1962. Fixa a parte pedagógica dos currículos mínimos relativos aos cursos de licenciatura. (pp. 95-100). Brasília: Documenta n. 10, 10 dez.

Brasil (1969). Resolução n. 12 de 19 de novembro de 1969. Fixa, para os cursos de licenciatura, o conteúdo e duração das disciplinas pedagógicas e baixa normas para sua aplicação. Belo Horizonte: Coordenação de Ensino e Pesquisa da UFMG.

Candau, V. M. F. (Coord.). (1987). Novos rumos da licenciatura. Brasília: INEP/PUC-RJ.

Conselho Federal de Psicologia. (1988). Quem é o Psicólogo Brasileiro. São Paulo: Edicon.

Fontoura, M. H. Silva, J. C. (2013). O ensino de Psicologia inserido nos cursos técnicos: Um relato de experiência através da docência em Psicologia do trabalho. Revista Reflexão e Ação, Santa Cruz do Sul, 21(esp.), 242-260. Recuperado de https://online.unisc.br/seer/index.php/reflex/article/view/2480/3003

Gondim, S. M. G., Bastos, A. V. B., \& Peixoto, L. S. A. (2010). Áreas de atuação, atividades e abordagens teóricas do psicólogo brasileiro. In A. V. B. Bastos \& S. M. G. Gondim (Orgs), O trabalho do psicólogo no Brasil (pp. 174-199). Porto Alegre: Artmed.

Izidoro, I. R., Jorcuvich, D. I., \& Costa, J. B. O. (2015). O retrato da licenciatura em Psicologia no Brasil. Congresso Nacional de Educação, Curitiba, Paraná, Brasil, 12. Recuperado de http://educere.bruc.com.br/arquivo/pdf2015/20784_9291.pdf

Lemos, L. S. (2008). A identidade do licenciado em Psicologia: Uma análise das regulamentações brasileiras entre 1962 e 2008. (Dissertação de mestrado). Faculdade de Educação da UFMG, Belo Horizonte, MG, Brasil. Recuperado de https://repositorio.ufmg.br/handle/1843/IOMS-7LRGMN

Passos, I. C. F., Goulart, M. S. B., Braga, F. M., Abreu, M. A., \& Vasconcelos, E. M. (2009). A formação em Psicologia da Universidade Federal de Minas Gerais e o processo de reforma psiquiátrica em Minas Gerais, nas décadas de 60, 70 e 80. Memorandum, 17, 149-168. Recuperado de https://periodicos.ufmg.br/index.php/memorandum/article/view/6671/4245

Romanelli, O. O. (2006). História da Educação no Brasil (30nd ed.). Petrópolis: Vozes. 
Souza, J. V. A. (2016). Licenciaturas da UFMG no período 1968-1996. In L. M. Faria Filho, J. V. A. Souza, \& N. M. L. Fonseca (Orgs.), Formação docente na UFMG: História e memória. Belo Horizonte: Mazza Edições.

\section{Endereço para correspondência}

\section{Deolinda Armani Turci}

Faculdade de Educação da UEMG

Rua Paraíba, 29, Funcionários, Belo Horizonte - MG, Brasil. CEP 30130-150

Endereço eletrônico: deolinda.turci@uemg.br

\section{Sérgio Dias Cirino}

Departamento de Psicologia da UFMG

Avenida Presidente Antônio Carlos, 6627, Pampulha, Belo Horizonte - MG, Brasil. CEP 31270-901

Endereço eletrônico: sergiocirino99@yahoo.com

\section{Érika Lourenço}

Departamento de Psicologia da UFMG

Avenida Presidente Antônio Carlos, 6627, Pampulha, Belo Horizonte - MG, Brasil. CEP 31270-901

Endereço eletrônico: erikalourenco.mail@gmail.com

Recebido em: 04/06/2019

Reformulado em: 22/08/2019

Aceito em: 01/09/2019

\section{Notas}

* Doutora em Psicologia pela UFMG. Professora/Pesquisadora da Faculdade de Educação da Universidade do Estado de Minas Gerais (FaE/UEMG).

** Professor Titular no Departamento de Psicologia da UFMG. Coordenador do Programa de Pós-graduação em Psicologia da UFMG.

*** Pós-doutora em Educação pela Pontifícia Universidade Católica de São Paulo (PUC-SP). Professora Adjunta do Departamento de Psicologia da UFMG.

${ }^{1}$ Nível de ensino entre o primário e o superior, correspondente, na atualidade, aos últimos anos do ensino fundamental e ao ensino médio. Segundo Romanelli (2006), a Reforma Francisco Campos organizou o ensino seriado com duração de 7 anos e dividido em 2 ciclos, o ciclo fundamental de 5 anos, com conhecimentos mais gerais, e o complementar de 2 anos, com conhecimentos mais específicos e preparatório para as faculdades de Direito, Medicina, Farmácia, Odontologia, Engenharia e Arquitetura. A Lei de Diretrizes e Bases da educação nacional de 1961 redividiu a educação escolar em três graus: educação de grau primário; educação de grau médio; e educação de grau superior. $\mathrm{O}$ ensino secundário, ou de $2^{\circ}$ grau, correspondia ao ginásio (4 anos) e ao colégio (3 anos no mínimo) (Brasil, 1961). 
${ }^{2}$ As DCNs foram estabelecidas pelo governo federal para os cursos brasileiros de graduação a partir da LDB de 1996, orientando a formação por competências e habilidades profissionais.

${ }^{3}$ Percebemos que, apesar dessa informação constar no Currículo Pleno da época, oficialmente a Faculdade de Educação só foi criada em 1968, quando os alunos da turma de 1964 já estavam no $5^{\circ}$ ano do curso. Divergindo da informação, nos históricos das disciplinas nas pastas dos alunos identificamos que essas disciplinas foram feitas ainda na própria Faculdade de Filosofia.

${ }^{4}$ De acordo com Souza (2016), com a reestruturação das universidades, em 1968, a UFMG criou essa faculdade, a partir do Departamento de Didática e Pedagogia, que cuidava da parte da formação pedagógica da FFCL e do curso de Pedagogia na ocasião.

Este artigo de revista Estudos e Pesquisas em Psicologia é licenciado sob uma Licença Creative Commons Atribuição-Não Comercial 3.0 Não Adaptada. 